\title{
E-learning as a Research Area: An Analytical Approach
}

\author{
Sangeeta Kakoty \\ NECRD, IGNOU, Guwahati \\ Guwahati, India.
}

\author{
Monohar Lal \\ School of Computer \& Inf. Sc. \\ IGNOU, New Delhi, India
}

\author{
Shikhar Kr. Sarma \\ Dept. of Computer \& IT \\ Gauhati University, Guwahati, India
}

\begin{abstract}
The concept of E-learning is very broad. It was coined in late 90s as the technological enhanced learning mechanism through Internet. Now it captures a broad range of electronic media like Internet, Intranets, Extranets, satellite broadcast, audio/video tape, interactive TV and CD-ROM to make the learning procedure more flexible and user friendly. Because of the flexible nature of E-learning, it has got more demand among the people of our country and the demand is increasing day by day. As the demand is increasing, this is the time to standardize the whole e-learning system in a proper way and the time to increase the quality of existing standards. Though many standards are already there and has accepted by many academia, institutes and organisations, still there are some gaps and works are going on to make them more practicable and more systematic.This paper analyses the current e-learning procedure and showing the new dimension of research work on this area that follows the important and most neglected research areas till today in this domain. It also analyses the importance of eeducation system and recent market of e-learning procedure.
\end{abstract}

Keywords- E-learning; learning standards; technology enhanced learning procedure; e-education system; dimension of research areas.

\section{INTRODUCTION}

This is the age of WWW and we are living in a globalized era, where the world is massively being connected. The Elearning initiatives have connected the whole world and have removed the barrier of age, place, time and socio-economic nature. The technological revolution has created a new dimension in whole education scenario. With the amazing development of Internet, the field of education has tried to exploit web as a communication channel to connect distant learners with their learning resources. Tom Kelly quoted that "E-learning is about information, communication, education and learning" [20]. It is a platform with flexible learning using Information Technology and Communication (ITC) resources, tools and applications, and focusing on interactions among teachers, learners and online environment [1]. E-learning usually refers to structured and managed learning experiences, and may involve the use of Internet, CD-ROMs, software, other media and telecommunications. Because of the flexible nature of E-learning and since it provides the right information in right time and in right place, students are now more familiar and feel more comfort in this new education system.

As the technology is advancing, the demand of online learning is also increasing. The technologies, tools, techniques, methodologies and standards are advancing in such a way that it has to overwhelm the ability of educationists to isolate, study, and report on the best methods to be used for any given audience [2]. With all these advances, the prospects for ELearning are clearly bright and many.

Though E-learning concepts have become more popular and many standards have been developed and used by many institutions and organizations, the real challenges facing many problems [6]. It is sure that many of standards developed in appropriate theoretical frameworks and formal approaches which guarantee that people do not stop merely at creating technical solutions, but can force on to document the impact of technology on learning, and can pass along with lessons learned. Further, in a developing country like India, the digital divide is still with us, and appropriate use of technology requires consideration of a wide range of low-tech and hightech solutions [4]. Many researches in this domain are still trying to make the content representation standard. They are trying to make the learning style more powerful from the learner's point of view which is more important area of research where learner's preferred pace is getting more interest than other areas.

Through this paper, author is trying to establish the line and type of research work in E-learning environment that people are working on. It focuses mainly the prospective areas of research in this domain. Though E-learning is a very broad area, we are concentrating and focusing the education system only which is the more promising area of whole E-learning scenario. We start this paper with an introductory note on the relationship between e-learning and education system. It followed by the recent market and its growth in this developing country. Section IV and section V is all about the discussion on prospects and promising research areas of e-learning domain.

\section{The Educational System AND E-LEARNING}

The popularity of Internet along with the extensive development of standard protocol and services creates a new dimension in the whole education scenario. It makes the online education more attractive. Everyday new approaches are coming and bringing new prospects in education and trying to refining the system towards personalized self-learning [3]. The benefits of E-learning are mainly the cost efficiency, accessibility and flexibility. However, whilst much has been made of the benefits to the organization of e-learning, there has been little, if any, qualitative investigation into the attitudes and views of the users themselves [14]. According to a research study in Europe, it has been seen that E-learning course 
effectiveness is $93.5 \%$, and $92.5 \%$ says that course completion in this system is not critical. The United States Distance Learning Association says, "Distance learning encompasses all technologies and supports the pursuit of lifelong learning for all" [13]. Canadian educator George Siemens launched a weblog and newsletter called eLearnSpace covering developments in e-learning technology and deployment. The website also includes comprehensive guides for educators that want to integrate e-learning tools and techniques into their institutions. Training Watch is an E-learning database where numerous volunteers contribute for the corporate e-learning community. The front page of this site offers visitors a rolling feed of e-learning news and analysis from a variety of sources. Readers provide instant feedback and ratings, highlighting some of the critical debates within the e-learning industry. It also contains numerous product reviews and field reports, ideal for managers that want to evaluate potential e-learning solutions for their organizations. Now-a-days there are different online portals; various websites are available for online news letters, online education, latest research findings to support both corporate and education sectors.

"E-Learning Centre Resource Guide" is the UK's most prominent online source for e-learning information offers a comprehensive guide to commonly available tools, software, and other resources. In addition to listing highly specialized resources, this e-learning guide offers tutorials for creating educational and professional development content using common, off-the-shelf computer software packages. There are different e-learning consultants like Jay Cross that maintains daily weblogs to share recent findings, William Horton Consulting inc. to help businesses, schools and governments in implementing effective e-learning programs, Maxine Morse, a leading learning consultant of Europe to help large organizations to develop effective e-learning strategies both for students and employees.

Now this is the time to standardize the whole e-learning system and to do this there are some standards bodies like Advanced Distributed Learning (ADL), IEEE Learning Technology Standards Committee and Instructional Management Systems (IMS) Project. They are the key players and mainly taking initiatives for this. Apart from them, another two organizations are also working on specifications related to e-learning are Alliance of Remote Instructional Authoring and Distribution Networks for Europe (ARIADNE) and Aviation Industry CBT (AICC). The most popular SCORM standard is developed to focus on the opportunity to create learning content, which may be reused, accessible on multiple levels, interoperable. It was developed to incorporate several, disparate efforts to develop standards for learning technology initiatives.

\section{MARKET OF E-LEARNING}

The whole online learning education industry we can divide into three major market segments:

- Content organisations: firms that furnish course structure, multimedia, simulations, testing and assessment; both offthe-shelf solutions as customized applications.
- Learning services firms: firms that provide needs assessments, program-building components, contentdesign, development and programming, technical and systems integration, site management and hosting, maintenance and online mentoring.

- Delivery solutions companies: firms selling technologies associated with e-learning, including training, authoring tools, course management systems, collaborative software and virtual classrooms and add-on tools.

Growing demands for e-learning require a combination of methodologies, tools, and technologies to effectively scale by e-learning development throughout the organization. IDC forecasts that the e-learning market, which was about $\$ 6.5$ billion in 2003, is increased to more than $\$ 21$ billion by 2008 , and will hit $\$ 52.6 \mathrm{~B}$ by 2010 . The 2007 U.S. e-learning market is presently $\$ 17.5$ billion [15]. The U.S. enterprise e-learning adoption accounts for 60 percent of the market, while Europe's accounts for 15 percent, overall usage of e-learning in Asia are expected to reach a compound annual growth rate of 25 percent to 30 percent through 2010. According to an education sector report by CLSA Asia Pacific Markets, the e-learning market size is estimated at $\$ 27$ million or Rs. 105crore, which is projected to grow to $\$ 280$ million or Rs. 1,092 crore by 2012 [17]. Comparing this to the size of the US e-learning market valued at $\$ 4$ billion or Rs 15,600 crore, and it may appear rather small, but the potential for growth in India given the huge population, lack of educators, etc, is much more. Meanwhile, the current e-learning global market size is over $\$ 20$ billion (Rs 78,000 crore) grown ten-fold since 2000, and is expected to surpass $\$ 52.6$ billion (Rs 2,05,000 crore) by 2010 . Online tutoring, on the other hand, is a $\$ 4$ billion (Rs 15,600 crore) industry and is growing at a rate of $10 \%-15 \%$ per annum according to Financial Express [15]. Computer-based learning on the other hand, still has a market size of $\$ 150$ million (Rs 590 crore), in India which is expected to grow to $\$ 750$ million (Rs 2,900 crore) by 2012, according to the CLSA Asia Pacific market report [26]

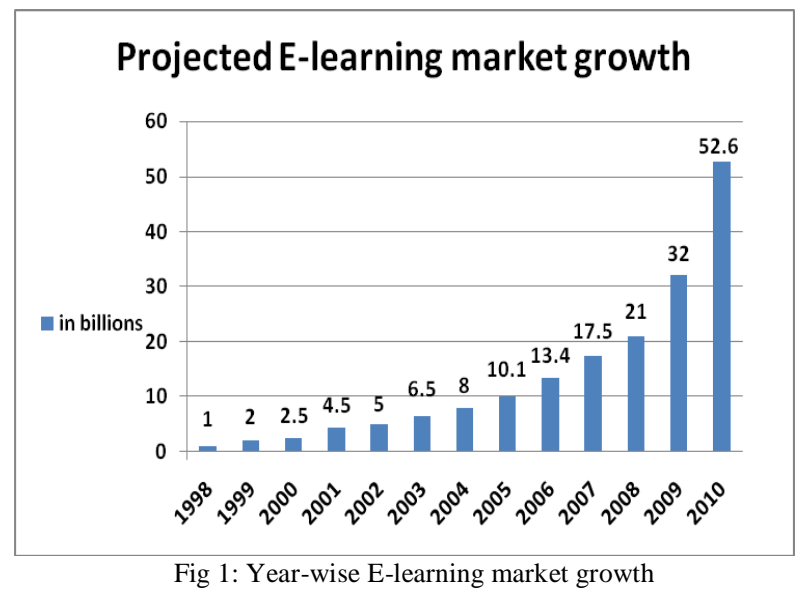

If we project the growth of e-learning from the year 1998 to 2010 , according to the value cited by different sites in different times, it has been seen that it always follows an increasing graph. This increasing growth is clearly viewed in the above graph. 
According to Training Magazine report, training organizations are shifting their staffing models away from a dominant focus on trainers and are now more focused on design, e-learning, and service and support activities. In addition, they are now outsourcing much of the delivery. A few years ago, more than 70 cents of every training dollar went to payroll. Today the figure is about 65 cents. Training magazine also reported that e-learning now accounts for 15 percent of all training delivered, which is a two-fold increase from just one year ago, and signifies that e-learning is here to stay as a mainstream training delivery vehicle. Meanwhile, classroom training has dropped from 70 percent to 62 percent; however, it still remains the dominant form of training [26].

ASTD's 2010 State of the Industry Report shows that elearning is still increasing as it now accounts for 27.7 percent of corporate training, its highest level since ASTD began collecting data on the use of technology for this report 14 years ago and in 2008, it was 23.1 percent [8].

In the 2010 market, corporations are the top buyers of Selfpaced eLearning. By 2015, corporations will still be the top buyer, followed by higher education and the PreK-12 buyers [5].

\section{PRospects OF E-LEARNING}

The current promising application areas of e-learning are content management and web security. Guild research report 2006 also focus that "Improving the quality of learning contents" gets the highest priority than other areas [22]. According to Blezu and Popa (2008), E-learning has lots of prospects in various sectors like: in dynamism, in real time, in collaboration, global reach and delivery of speech [10]. This is because in this domain:

- Learners can access information that is correct and up to date through the web, information databases or university or company intranets.

- Learners are able to meet in a virtual space with other members and practitioner experts to discuss issues, answer questions and even participate in simulations and management games without having to leave their office or home.

- Learners benefit from learning when required, learners are able to access the right sort of training at the right time with the right people.

- Learners have access when they want it.

- Learners have access to the same materials.

- Learners regardless of where they are receive the same message and are able to engage other learners and practitioners globally.

Guild Annual Research Report, April 2006 was on the subject of future directions in e-learning. From their survey sample it was noticed that "designing and developing elearning content" activity will get more focus and attention in future. The second highest priority, according to this report is the "addressing learner requirements and preferences" [22]. For an organization, "Extend the global reach of the E-learning content" is the focusing priority area to get the content out beyond the geographical limit. In that report it was clearly written that "Blended learning" will grow significantly in the year ahead.

\section{RESEARCH IN E-LEARNING}

E-learning is the education through distance mode where many technologies can employ. Though e-learning and distance education are both separate terms, they are quite same. Only difference is that distance education separates the students from traditional classroom environment whereas in e-learning environment it is not. So, research in distance education can help indirectly the whole e-learning procedure. It is seen that, research in distance education has been subject to consistent critique [9] [19] [24]. It has even been characterized as "theoretical and predominantly descriptive" [21]. Richter argues in his paper that in the field of distance education, a validated meta-structure of research topic is lacking, i.e., a map of research areas that would help to organize the body of knowledge in the field. The structure of a research discipline forms the foundation for identifying gaps and priority areas for researchers [23].

Ardil introduced an e-learning collaborative circle for teachers and students to announce their research subjects/projects through a cyberspace where members can interact creatively and freely to consider relevant issues, sharing individual experiences and providing and gaining support from each other [7]. Designing and developing distance education programs requires specialized training and skills. This is more so in case of online learning [11]. Because of this, researchers are still trying to improve and manage the learning contents and trying to give one standards of it. SCORM of ADL is the popular standard of content packaging and communication than other standards like IMS content packaging application and IMS simple sequencing specification. Though SCORM is accepted by many organizations and academia, work is still going on to improve the standards. Though the learning content is sequenced in SCORM standard now, the course creator must understand the use and manipulation of its complicated sequencing rules which is the main barrier for most of the course creator [18].

The learning standards and specifications of whole elearning procedure can be organized into five sub-branches: metadata management, content packaging and communication, learner profile, learner registration and security [16]. For each and every branch there should be some standards. Since user can purchase based on their quality and appropriateness and with confidence that they will work on it effectively, we should have to think according to their interest and accordingly have to design their standards. They should be user friendly and more interactive. Several initiatives have been taken into account in making the e-learning standards more attractive and assistive.

The metadata standard named "Learning Object Metadata (LOM)" of IEEE is adopted by many organizations. The initiatives "dealing with content packaging" are the IMS content packaging specification, IMS simple sequencing specification and ADL SCORM model which is more popular than other two. Learner profile is the most important section of e-learning procedure and effort is going on to make it standardize. One another important effort in standardization of 
whole e-learning scenario is the IMS learner information package (LIP) specification. For learner registration, there are two initiatives currently dealing with: the IMS Enterprise Specification and the Schools Interoperability Framework which supports on the exchange of the data into K-9 environment (http://www.imsproject.org). When content is launched, it needs to communicate learner's data and previous browsing activity and information. There should be some system to monitor all these activities. Work is going on in this context and is applying in the popular standard model SCORM of ADL. The latest release of ADL is the SCORM 2004. It includes the intelligent tutoring system (ITS) that works as natural human tutors [12]. ADL is actively engaging in research and implementation of digital knowledge environment of future in the area of standards and authoring tools. AICC's new release Package Exchange Notification Services (PENS) can define an interface between authoring tools and LMS systems to automate publishing and testing of learning materials accessed through LMS system. Kakoty and Sarma, 2011 argues in their previous paper that by integrating Expert System technology the whole e-learning system will be more learners centric and assistive for learner [14].

There should be a functional model to understand how different systems will work in e-learning environment and for that SCORM is the highly generalized model that manages the delivery and tracking of learning content to a learner, but does not specify functionality within the learning management system (LMS). So, Liu et el. in their paper proposed one advanced functional model of SCORM to define which information would interchanged among each component [16]. Likewise it is very much important to improve the functions of existing standards by applying different ICT tools.

Richter (2009) has done one Delphi study on possible research areas in distance education for which he classified whole distance education research into three broad meta-levels:

\section{A. Macro level : the system and theories}

\section{B. Meso level : management, organisation and technology}

\section{Micro level : teaching and learning}

These three levels he again classified into 15 sub areas according to the importance of the research issues and has given rating of importance from 1 to 10 as 1 labeled for "very low importance" and 10 labeled for "very high importance" [23].

\section{ANALYSIS AND RECOMENDATION}

From the study it has seen that content packaging and content managing is got the highest priority in e-learning research where yet lots of development has to be made. Learner's prospect and interest is increasing very rapidly as the technology is growing. Now researcher has to design the learning methodology according to learner's interests and preferences. For that learner characteristics, their behavior, their learning style has to study which is possible by recording their browsing history at their learn time. That is why now the research on learner characteristics has got widest and highest ranges of rating. Again, the two areas like "access, equity and ethics" and "quality assurance" are of growing interest.
Based on the Delphi report of Richter, the most neglected areas of e-learning are the cultural differences in global distance learning programs and cooperation which should receive much more attention. So from this study it has been seen that globalization of education, cross-culture aspects and culturally complex student support system in distance education as well as in e-learning environment is a prospective research area. We can improve these areas by integrating new technologies and ICT tools. There is also a need for international comparative research in this environment.

A promising technology for realizing e-learning requirements is the Semantic web that can provide flexible and personalized access to the learning materials. In fact, semantic web can be exploited as a very suitable platform for implementing an e-learning system, because it provides all means for e-learning: ontology development, ontology-based annotation of learning materials, their composition in learning courses and proactive delivery of the learning materials through e-learning portals [25]. Since e-learning involves a number of forms, number of complex steps, varying level of interest of learner, there should be a system to take decision at every level and at every stage of learning which can make the system more interactive for learner. A Decision Support System (DSS) is an interactive information system that provides information, models and data manipulation tools to make help decisions in semi-structured and unstructured situation [28].

\section{CONCLUSION AND Future PROSPECTS}

As e-learning is definitely a growing field in the educational and training market and e-learning standard is a new emerging area, there are many challenges in implementation of undergoing technological changes and developments. The security of services, the encryption of messages and the common taxonomies to describe services and service access points in e-learning systems environments are all in need of consideration. However, Supporters of e-learning are always looking forward some new developments. Technology advancements will continue to reshape learning over the Internet with increasing use of advanced tools and techniques.

So by employing the new technology in e-learning environment, one can make the system more attractive and interactive for learner that may help to build a learner centric platform in this environment.

\section{ACKNOWLEDGEMENT}

The first author acknowledges the academic and financial support given by North East Centre for Research and Development (NECRD), IGNOU, Guwahati for the research work.

\section{REFERENCES}

[1] S. Codone, “An E-learning Primer”. Pensacola, Florida, 2001.

[2] "The E-learning e-revolution in colleges and universities". A PanCanadian Challenge, 2001.

[3] A.E. Blackhurst, and D.L. Edyburn, "A brief history of Special Education Technology" Knowledge by Design Inc., 2000.

[4] "E-learning quality: Aspects and criteria for evaluation of e-learning in higher education", Report 2008:11R, Swedish National Agency for Higher Education, 2008. 
[5] S. Adkins, "The US Market for Self-paced eLearning Products and Services: 2010-2015 Forecast and Analysis" Ambient Insight, LLC, January 2011

[6] I. E. Allen, J. Seaman, "Online Nation: Five Years of Growth in Online Learning". Needham, MA: Sloan Consortium, 2007.

[7] C. Ardil, "E-learning Collaborative Circles", International Journal of Humanities and social Services, Vol. 1, No. 4, 2007.

[8] ASTD State of the Industry Report. Retrieved December 1, 2010

[9] R. M. Bernard, P. C. Abrami, Y. Lou, and E. Borokhovski, "A methodological morass? How we can improve quantitative research in distance education”, Distance Education, 25(2), 175-198, 2004.

[10] C. Blezu, and E. M. Popa, "E-Learning and its Prospects in Education" 12th WSEAS International Conference on COMPUTERS, Heraklion, Greece, July 23-25, 2008.

[11] J. Dikshit, A. Gaba, S. Bhushan, S. Garg, and S. Panda, "learning Attitude, Motivation and Preferences of Online Learners" Indian journal of Open Learning 12(3), 149-167, 2003.

[12] K. R Ellis, "E-learning Standards Update" learning circuits, 2005.

[13] P. Gledhill, "Latest e-Learning research in Europe Middle East and Africa" (page 1 of 3), 2004.

[14] S. Kakoty, and S.K Sarma. "Expert System Applications in E-learning Environment: Analysis on Current Trends and Future Prospects" International Journal of Internet Computing (IJIC), Vol. 1, 90-93, 2011.

[15] D. Kopf, e-Learning Market to hit $\$ 52.6 \mathrm{~B}$ by 2010 . The Journal: July 2007.

[16] X. Liu, A. E. Saddik, and N. D. Georganas "An implementable architecture of an e-learning system" Proceedings of Canadian Conference on Electrical and Computer Engineering, May 4-7, 2003, 2, pp.943-946., 2003.

[17] M. McGee, "E-Learning Predicted To Recover--Again". Information Week: Nov, 9, 2004.

[18] M. Melia, , Barrett, R. and Pahl, C "A Model-based Approach to SCORM Sequencing" In Proceeding of the Sixth Annual Irish Educational Technology User's Conference (EdTech06), 2006.

[19] M. G. Moore, "Some observations on current research in distance education" Epistolodidaktika, 1, 35-62, 1985.

[20] Namahn. "E-learning: A research Note" http://www.namahn.com/resources/documents/note-e-learning.pdf

[21] H. Perraton, "Rethinking the research agenda", International review of Research in Open and Distance Learning, 1(1), 2000.

[22] J. Pulichino, "Future directions in e-Learning research Report 2006", The Learning Guild Research 2006.

[23] O. Z Richter, "Research Areas in Distance Education: A Delphi Study", International Review of Research in Open and Distance Learning, Vol. 10, No. 3, 2009.

[24] F. Saba, "Research in Distance Education: A status report", International review of Research in Open and Distance Learning, 1(1), 2000.

[25] L. Stojanovic, S. Staab, and R. Studer, "E-learning based on semantic web" WEBNET 2001, 2001.

[26] Training Magazine "Training Industry Report". Retrieved August 7, 2007.

[27] "E-learning for Innovation: Executive Summary", Helios yearly report 2007.

[28] M. S. Velmurugan and K. Narayanasamy "Application of Decision Support System in E-commerce", Communications of the IBIMA, Volume 5, 2008

\section{WEBSITES REFERRED:}

[1] http://www.imsproject.org.

[2] http://www.adlnet.org.

[3] http://www.worldwidelearn.com/elearning-industry/articles.htm

[4] http://www.LlearningGuild.com

[5] http://www.namahn.com/resources/documents/note-e-learning.pdf

[6] http://www.nwlink.com/ donclark/hrd/elearning/growth.html

[7] http://www.astd.org/TD/Archives/2010/Nov/Free/1110_2010+State+of+ the+Industry.htm

[8] http://www.trainingmag.com/managesmarter/images/pdfs/IndRep06.pdf

\section{AUTHORS PROFILE}

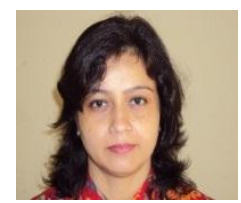

Sangeeta Kakoty received the B. E. Degree in Computer Science and Engineering from Jorhat Engineering College, Assam in 1995. She received M.Sc. and M. Phil degree in Computer Science from Gauhati University, Assam and from Vinayaka Mission University, Tamil Nadu in 2004 and 2007 respectively.

She was working as a lecturer in The Department of Computer Sc., Jagiroad College, Assam since 2005. She got the Research and Teaching Assistant (RTA) fellowship from IGNOU, New Delhi. Now she is a research fellow of

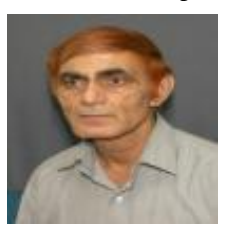
IGNOU and working as a RTA in NECRD, IGNOU since 2008. Her main interest includes Expert Systems and Data Mining.

Prof. Manohar Lal is a product of IIT Kanpur, IIT Delhi and University of Delhi. He completed his MTech in Computer Science and Engineering (CSE) from IIT Kanpur; pursued his second PhD in CSE from IIT, Delhi. Earlier, he completed his master's and $\mathrm{PhD}$ programmes in Mathematics from University of Delhi. He has vast teaching experience of more than 42 years at various universities including University of Delhi and JNU. He has been Professor and Head of Computer Science Department and Director, Computer Centre/Division at HP University, Shimla as well as MD University, Rohtak. Prof. Lal has long research experience. Earlier he worked in the area of 'Error - Correcting Codes' (a branch of networking/Data Communications). Currently he is working in the areas of 'Automation of Reasoning' (a branch of Artificial Intelligence) and Computer Networks. He has large number of publications in these areas in national and international journals of repute and has been guiding research students in these areas. Also he is associated with large number of academic bodies in various capacities. Dr. Lal is with IGNOU

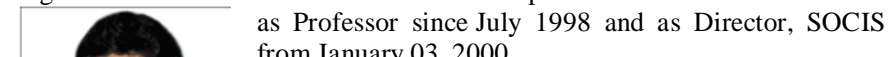
from January 03, 2000.

Prof. Shikhar Kr. Sarma got his Ph.D. in the field of computer networks from Gauhati University, India. He is currently holding the position of Professor and Head of Department of Computer and Information Technology at Gauhati University, India. His earlier assignment includes Indian Institute of Technology Guwahati, India, Rajiv Gandhi Central University, India, and Debub University, Ethiopia. His current research areas are NLP and Expert Systems. He holds many major research funding including the Language Technology Development Project, Local Language Search Engine Development Project of Ministry of Communication and IT, Govt. of India etc. He has written numerous research papers, and currently guiding 12 Ph.D. Students. 